\title{
Mythbusters
}

\section{Myth: Mammography for Breast Cancer Screening - Are We Doing More Harm Than Good?}

\author{
Mark Corkum \\ Class of 2015, Faculty of Medicine, Dalhousie University
}

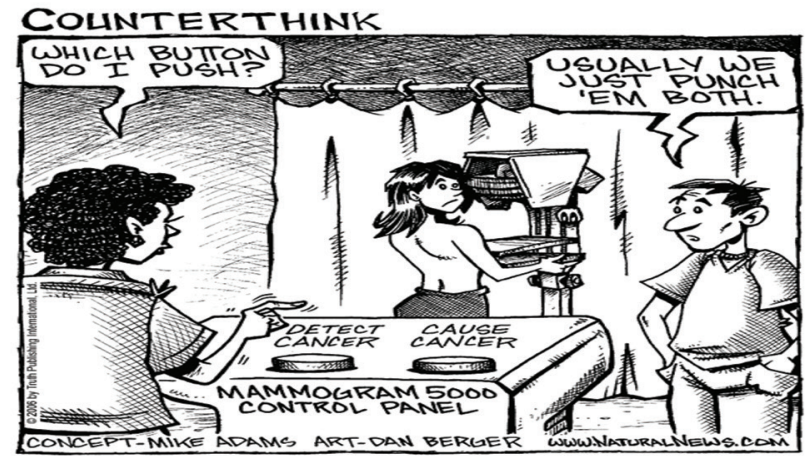

Early detection saves lives. Logically, this statement makes sense. If we could detect breast cancer earlier with a positive mammogram than it would have been detected as a lump in the breast, the cancer would have less time to have spread to surrounding or distant sites. As survival is directly linked with the degree that the cancer has spread from the initial tumour site at diagnosis ${ }^{1}$, we expect mammography to reduce breast cancer mortality. Public opinion largely favours this logic, and the mantra of early detection saves lives resonates throughout breast cancer awareness groups. ${ }^{2,3}$ Many compelling breast cancer survivor stories state "Mammography has saved my life". These stories are common; on average, one cancer survivor story was published every month in 18 daily newspapers and magazines sampled over a four month period. ${ }^{4}$

For decades, this public opinion was congruent with scientific evidence and opinion on mammography. However, on November $16^{\text {th }}$, 2009, the U.S. Preventive Services Task Force released controversial recommendations on mammography screening, no longer recommending women aged 40-49 to receive mammograms, as was previously advised. ${ }^{5}$ Other recommendations, including for women to receive a mammogram every two years between the ages of 50 and 74 , and ceasing mammography screening at age 75 remained unchanged. These recommendations were later mirrored by the Canadian Task Force on Preventive Health Care. ${ }^{6}$

These decisions were made in light of recent evidence that mammography may not be as effective in reducing breast cancer mortality as previously thought. In addition, some argue that mammography in any average

risk age group may be causing more harm than good as a consequence of overdiagnosis and overtreatment of breast cancer. In this Mythbuster, I will examine the evidence both for and against the effectiveness of mammography in breast cancer screening, with the goal of providing physicians with a succinct review on this now-controversial topic, allowing them to discuss both the benefits and potential harms of mammography screening with their patients.

The effectiveness of mammography in detecting breast cancer has been studied in over 600,000 women in many large randomized controlled trials. The most comprehensive systematic review and meta-analysis of these studies to date found a 19\% decrease in breast cancer mortality due to mammography. ${ }^{7}$ In addition, a measurable a decline in breast cancer mortality rates has occurred in the past few decades. ${ }^{8-11}$ In Canada, breast cancer mortality has fallen by almost $40 \%$ between its peak in 1986 to the most recent estimate in 2012. ${ }^{1}$ Earlier detection of breast cancer due to mammography has received much of the praise for this decline. However, many improvements in breast cancer treatment and increased breast cancer awareness have also occurred over the same time period. How much of the observed decrease in breast cancer mortality can be attributed to mammography screening?

The best evidence to answer this question comes from Norway, where mammographic screening was implemented in a systematic geographic manner over a time period of 9 years. ${ }^{12}$ This study found that long-term breast cancer mortality was reduced by $28 \%$ in the areas with mammography screening. However, breast cancer mortality was also reduced by $18 \%$ in the population which did not have access to mammography screening over the same time period. Therefore, mammography was only responsible for a third of the reduction in mortality observed after implementing a screening program, and only reduced breast cancer mortality by $10 \%$ in this population. The other $18 \%$ in decreased mortality can be attributed to improved treatments 
and breast cancer awareness. A recent study estimated that only $13 \%$ of women with breast cancer detected by mammography actually had their life saved because of the mammogram. ${ }^{15}$

After implementing a mammography screening program, we would expect to see fewer of late-stage breast cancer diagnoses along with an increase in earlystage diagnoses. While mammography has detected significantly more earlier-stage breast cancers ${ }^{13}$, analysis of time trends in late-stage breast cancer diagnoses has found that the incidence of late-stage breast cancer diagnoses has not decreased, and instead has remained level after the implementation of mammographic screening. ${ }^{14}$

There are many potential harms of mammography screening. False-positive tests results, when a mammogram suggests that breast cancer may be present but upon further investigation it is determined that no cancer is present, lead to significant psychological distress. ${ }^{16}$ Overdiagnosis and overtreatment occur when a woman is diagnosed with breast cancer, which is actually present (i.e. it isn't misdiagnosed), but the cancer would have never caused symptoms or a risk of death. This occurs because mammograms preferentially detect slow growing breast cancers that would have never put the patient at risk from dying of breast cancer, known as length bias. ${ }^{17}$ It has been estimated that over the last 30 years in the United States, 1.3 million women have been overdiagnosed and overtreated due to mammography detection of breast cancer in the last 30 years. ${ }^{18}$

How can we put these risks in perspective? Of 2000 women who are invited for mammography screening for a 10 year period, one woman will have her life prolonged because of mammography. ${ }^{7}$ However, 10 women will be overdiagnosed with breast cancer and treated unnecessarily, which would not have been diagnosed if she wasn't screened screening. 200 women will receive a false positive result over this time period, leading to significant psychological distress. ${ }^{16}$ Clearly, these risks are significant when compared to the benefits of mammography screening.

Therefore, we can see that the benefits of mammography screening for detecting breast cancer aren't as clear cut as previously thought, and there is substantial evidence that there are many harms that are associated with mammography screening. While professional opinions greatly differ on the balance of the benefits and potential harms, ultimately the decision of whether to undergo mammography screening must lie entirely with the patient. The patient should be informed of both the benefits and potential harms associated with mammography screening, and make a decision based off of their own personal values and beliefs of mammography.

\section{Search strategy of PubMed \\ (1) "Mammography" $[\mathrm{MeSH}]=22600$ \\ (2) "Early Detection of Cancer" $[\mathrm{MeSH}]=4881$ \\ (3) "Breast Neoplasms/diagnosis" [Majr] = 52585}

$\{1$ AND 2 AND 3$\}=460$

Limited to published articles in the last 5 years $=455$

Limited to reviews, systematic reviews and meta-analyses $=65$

In addition to this systematic review search, I also retrieved articles from the reference list of reviews found from my search results.

\section{References}

1. Canadian Cancer Society's Steering Committee. Canadian Cancer Statistics 2012. Toronto: Canadian Cancer Society; 2012.

2. Canadian Breast Cancer Foundation. Risk Reduction and Early Detection Saves Lives. Available at: http://www.cbcf.org/prairies/ AboutUsMain/MediaCenter/Newsletters/Summer-2010-eNews/ Pages/Risk-Reduction-And-Early-Detection-Saves-Lives.aspx. Accessed March 1st, 2013.

3. B4Pink. About B4Pink. Available at: http://www.b4pink.com/ index.php/about-us/. Accessed March 1st, 2013.

4. Kromm EE, Smith KC, Singer RF. Survivors on Cancer: the portrayal of survivors in print news. J Cancer Surviv 2007 Dec;1(4):298-305.

5. US Preventive Services Task Force. Screening for breast cancer: U.S. Preventive Services Task Force recommendation statement. Ann Intern Med 2009 Nov 17;151(10):716-26, W-236.

6. Canadian Task Force on Preventive Health Care, Tonelli M, Connor Gorber S, Joffres M, Dickinson J, Singh H, et al. Recommendations on screening for breast cancer in average-risk women aged 40-74 years. CMAJ 2011 Nov 22;183(17):1991-2001.

7. Gotzsche PC, Nielsen M. Screening for breast cancer with mammography. Cochrane Database Syst Rev 2011 Jan 19;(1):CD001877. doi(1):CD001877.

8. Schopper D, de Wolf C. How effective are breast cancer screening programmes by mammography? Review of the current evidence. Eur J Cancer 2009 Jul;45(11):1916-1923.

9. Chu KC, Tarone RE, Kessler LG, Ries LA, Hankey BF, Miller BA, et al. Recent trends in U.S. breast cancer incidence, survival, and mortality rates. J Natl Cancer Inst 1996 Nov 6;88(21):1571-1579.

10. Centers for Disease Control and Prevention. Breast Cancer Trends. Available at: http://www.cdc.gov/cancer/breast/statistics/ trends.htm. Accessed March 2nd, 2013.

11. Nova Scotia Breast Screening Program. Annual Report 2012 (2011 data). Available at: http://breastscreening.nshealth.ca/ann rpt_2012.pdf. Accessed March 2nd, 2013.

12. Kalager M, Zelen M, Langmark F, Adami HO. Effect of screening mammography on breast-cancer mortality in Norway. N Engl J 
Med 2010 Sep 23;363(13):1203-1210.

13. Esserman L, Shieh Y, Thompson I. Effect of three decades of screening mammography on breast-cancer incidence; Rethinking screening for breast cancer and prostate cancer. JAMA 2009 Oct 21;367; 302(21; 15):1685-1692.

14. Autier P, Boniol M, Middleton R, Dore JF, Hery C, Zheng T, et al. Advanced breast cancer incidence following population-based mammographic screening. Ann Oncol 2011 Aug;22(8):17261735.

15. Welch HG, Frankel BA. Likelihood that a woman with screendetected breast cancer has had her "life saved" by that screening. Arch Intern Med 2011 Dec 12;171(22):2043-2046.

16. Brewer NT, Salz T, Lillie SE. Systematic review: the long-term effects of false-positive mammograms. Ann Intern Med $2007 \mathrm{Apr}$ 3;146(7):502-510.

17. Fox MS. On the diagnosis and treatment of breast cancer. JAMA 1979 Feb 2;241(5):489-494.

18. Bleyer A, Welch HG. Effect of three decades of screening mammography on breast-cancer incidence. N Engl J Med 2012 Nov 22;367(21):1998-2005.

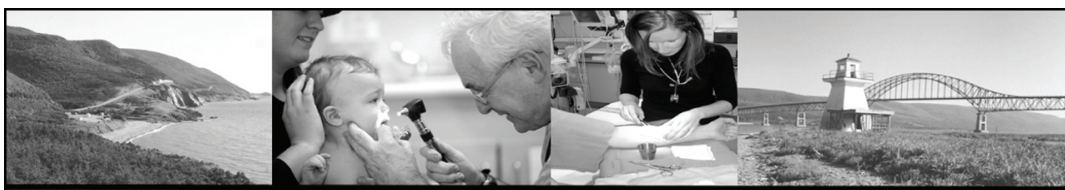

\section{Cape Breton Island Great Place, Great People, Great Life Physician Opportunities}

The Cape Breton District Health Authority has openings available in:

$\begin{array}{llllll}\diamond & \text { Emergency Medicine } & \diamond & \text { Family Medicine } & \diamond & \text { Pathology } \\ \diamond & \text { Medical Oncology } & \diamond & \text { Cardiology } & \diamond & \text { Radiology } \\ \diamond & \text { Palliative Care } & \diamond & \text { General Internal Medicine } & \diamond & \text { Hematology }\end{array}$

The District serves 130,000 people through a highly developed regional centre, providing a full range of secondary and tertiary services inclusive of Mental Health \& Addiction Services and a full service Cancer Centre . In addition, we have eight community and rural hospitals offering acute care and a wide range of primary care services. Cape Breton's natural beauty, diverse culture and year-round outdoor activities make the Island a vibrant place to live, work and play. Candidates must be eligible for licensure in Nova Scotia. Support is available for site visits and relocation.

Inquiries and applications to:

Dr. Rex Dunn, Vice President, Medicine

Cape Breton District Health Authority

1482 George Street, Sydney, Nova Scotia B1P 1P3

Fax: (902) 567-7255 E-mail: dunnr@cbdha.nshealth.ca

http://www.movetocapebreton.com/

Cape Breton District HEALTH AUTHORITY

Making Healthier Choices Together 